\title{
Assessing a Graduate Commons in the Library: Graduate Students Need an Identified Third Space
}

\author{
Susan Beatty \\ University of Calgary, Canada
}

\section{Introduction}

The University of Calgary is a four-year doctoral institution. In 2016-2017, there were 5,672 full time graduate students attending University of Calgary. ${ }^{1}$ While there are offices or work spaces in their departments for many graduate students, the space can vary greatly in terms of suitability, utility, access, and comfort. In fall 2016, in order to meet some of the need for space by graduate students, Libraries and Cultural Resources opened a newly renovated space, the Alan MacDonald Graduate Commons, a shared space intended to provide space for graduate students who are at the stage of intensive research and writing. Students registered late in the fall and were assigned swipe card access to the room to the end of April 2017. In order to determine the utility and effectiveness of the space and its features, students were surveyed in April 2017. Results showed that the students used the space to improve and enhance their learning, research and productivity output.

\section{Background}

The Taylor Family Digital Library (TFDL) at the University of Calgary (UofC) opened in 2011. It has become a hub on campus, attracting thousands of undergraduate students daily. The library features an assortment of student spaces over six floors, from group study rooms to study carrels, group conversation areas, workstations with PCs or Macs, and three floors of quiet study space with individual seating, table seating, and quiet classrooms with PCs available for use when not being used for instruction. While the library does attract some graduate students, there is not a large core of graduate students who come to the library to do their work. In a previous study, the author investigated use of informal learning spaces in the library. It was found that students have a variety of reasons for using the library and a variety of preferences when it comes to space, primarily determined by their learning goals of the day and their learning behaviour. ${ }^{2}$ So it was with some curiosity that the author devised a survey of the graduate students who were using the Commons to determine not only likeability and utility of the space and its features, but also to determine the students' learning space preferences and behaviours and how this new space suited their needs.

Recognizing that there was a need for graduate student space, the library converted a reading room to a graduate-student-only space, using university infrastructure money. Consulting with the Faculty of Graduate Studies to identify the needs of graduate students, the library created a secure space with flexible furniture, lockers, and comfortable seating. Information about the new space was distributed directly to graduate students and students were prompted to apply. Eighty-two students were assigned swipe card access to the room. The number was limited because the level of use of the space was unknown. Students were assigned one of the 56 lockers on a first-come, first-serve basis. The room features 24 small, rectangular, wired, moveable tables; adjustable chairs; 28 wired study carrels with individual lighting; and two adjustable-height individual tables with attached lighting. Individual privacy dividers for the tables are available. One wall is southwest facing, with windows providing natural light. If the sun is too hot or bright, the students can adjust the two types of screens: light filtering or blackout to block the sun. There is also overhead lighting. Students have swipe card access to the room whenever the library is open (8:00 a.m.-11:00 p.m., SundayFriday; 10:00 a.m.-11:00 p.m., Saturday). Cold food and covered drinks are allowed in the room. No seats/spaces are reserved, all is a first-come, first-serve basis. Total cost for the renovation, including electrical upgrade and paint, was approximately $\$ 200,000 \mathrm{CAD}$. 


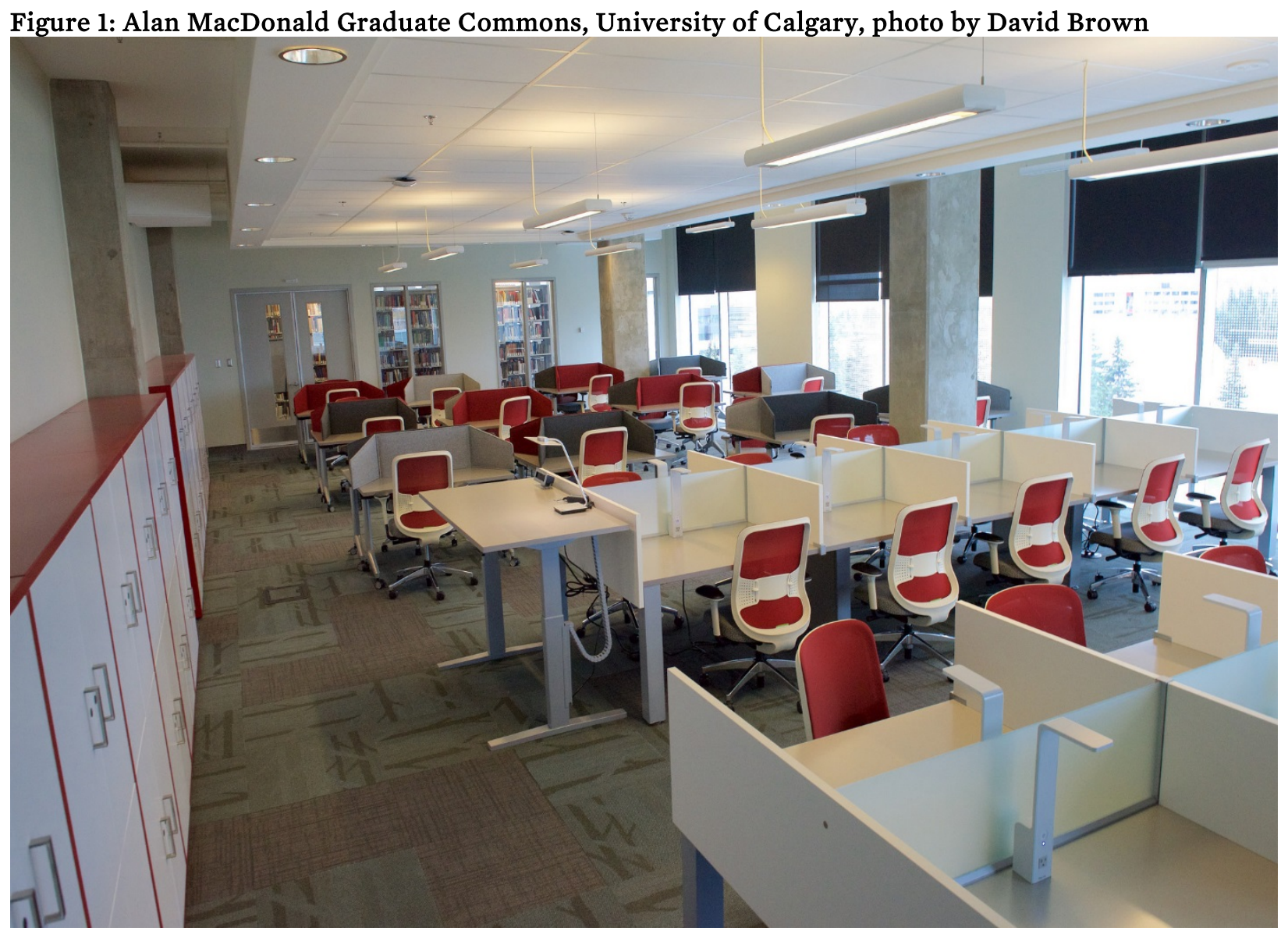

Figure 1 above shows the Commons with the windows to the right and lockers to the left. Carrels (in the forefront of the photo) are at the back of the room, and moveable tables with optional dividers in place are towards the front of the room. The door has swipe card access. Chairs are adjustable. This is a photo of the room without students.

In a recent survey of graduate services webpages in academic libraries in the United States, four of the five ARL libraries surveyed offer graduate study group space and all five offered graduate study individual space. ${ }^{3}$ While this is a small sample, it is generally recognized that graduate students prefer to have their own space, separate from the undergraduates. Kinsley, et al., in their study of graduate students' needs for spaces for research and study, found, among other things, that graduate students prefer their own space that is flexible, private, quiet, and comfortable, with an opportunity for distraction such as a window with a view. ${ }^{4}$ Students especially needed room to spread out and expressed a preference for laptops and large tables and access to electrical outlets. In an earlier study, Rempel, Hussong-Christian, and Mellinger identified graduate students' need for "spaces for them to be separate from undergraduates, comfortable and usable for extended time periods." ${ }^{5}$ Recognizing the need to establish a space that suits graduate students, Libraries and Cultural Resources at the University of Calgary established a separate space for quiet, individual work that was flexible and comfortable.

\section{Methodology}

Students $(\mathrm{N}=82)$ who registered to use the Graduate Commons were asked via email to complete an online survey. The survey asked the students to identify which elements of the space they preferred, the nature of the work that they accomplish in the space, length of stay, frequency of visits, and preferred times and days of the week for their visits. They were also asked to rate the features of the space and indicate their preferred seating and their activities. Additionally, students had space to comment on their goals in using the space and 
how the space compared to other graduate spaces on campus. In a study of undergraduate behaviours in library learning spaces at the TFDL, the author noted that there was a preference for certain types of spaces according to the learning goals of the student and the nature of their learning activities and goals. ${ }^{6}$ While undergraduate learning and graduate learning have different foci and outcomes, this author was also interested in discovering if there were any similarities between the learning behaviours and space preferences of undergraduate students and graduate students. This was explored somewhat in the survey by asking students to indicate what they were doing in the space, where they sat, and why they chose to sit where they did. Students were sent an initial letter of notification, a follow-up invitation with a link and informed consent, one reminder, and a final notice with thanks. The survey was open for two weeks.

\section{Results \\ Demographics}

Of the 44 completed surveys (53.6\% response rate), 31 respondents were female, 12 were male, and 1 preferred not to say. Twenty-seven (61.4\%) of the students were master's students and 17 were doctoral. Twenty students (45.5\%) were in the arts, humanities, and social sciences (AHSS) and 24 (55.5\%) were in the sciences, including engineering and health sciences. Of the 24 students in the sciences, 8 students were in various engineering departments, 4 students were in biosciences, 4 in chemistry. Of the 20 in AHSS, 3 were in English, 3 in history, and 3 in environmental design. The remainder were distributed throughout other disciplines.

\section{Frequency of Use}

Just over half of students $(\mathrm{N}=23)$ used the Commons two to four times per week. Ten indicated that they came to the Commons once a week or less, and 11 indicated a high frequency of over five times a week. There was a split between the number of visits in a day: 22 reported visiting twice a day and 18 reported coming just once a day. On average their stays were lengthy. Twenty-five students report staying four or more hours in a visit; 19 would stay one to three hours. Students were asked to indicate their preferred times. The most popular times were noon to four p.m. $(\mathrm{N}=32)$, followed by before noon $(\mathrm{N}=25), 4: 00-8: 00 \mathrm{p} . \mathrm{m}$. $(\mathrm{N}=21)$, and 8:00 p.m.-11:00 p.m. $(\mathrm{N}=10)$ in preference. When asked to choose their preferred days of the week, there was almost an even split over each day Monday-Friday (range 37-40), with the weekends (Saturday-Sunday) preferred by only 20. In terms of preference pattern for days of the week, 17 students preferred MondaySaturday and 13 preferred Monday-Sunday.

\section{Reasons for Using the Commons}

Students were asked to choose from a variety of reasons for using the Commons. While some ( $\mathrm{N}=12)$ indicated that they did not have any space elsewhere on campus, the majority of responses indicated a preference for the library because of access to resources, assistance, and services if needed. The space itself was desirable because of its comfort, newness, quiet, and lack of distraction.

\section{Where Do They Sit?}

Students preferred to sit near the windows at a solitary table $(\mathrm{N}=30)$, with about half of the table users indicating that they would use an optional table divider for more privacy. Eleven students indicated a preference for the study carrels and seven indicated a preference for the adjustable height tables. Fifteen indicated a preference for sitting away from the door at the far end of the room.

When students were asked why they sit where they sit, it is clear that the choice of near the window is not only for the light, but for the view which provides either a distraction or an opportunity to avoid distraction. They also prefer to work at a solitary table so that they are not distracted, as well as having enough room to work and to focus. This need for enough space and to avoid distraction is an echo of similarly-expressed undergraduate needs during times of intense learning. Some of the comments also reflect directly what the undergraduates also expressed: they select the space to work because it feels right. ${ }^{7}$ 


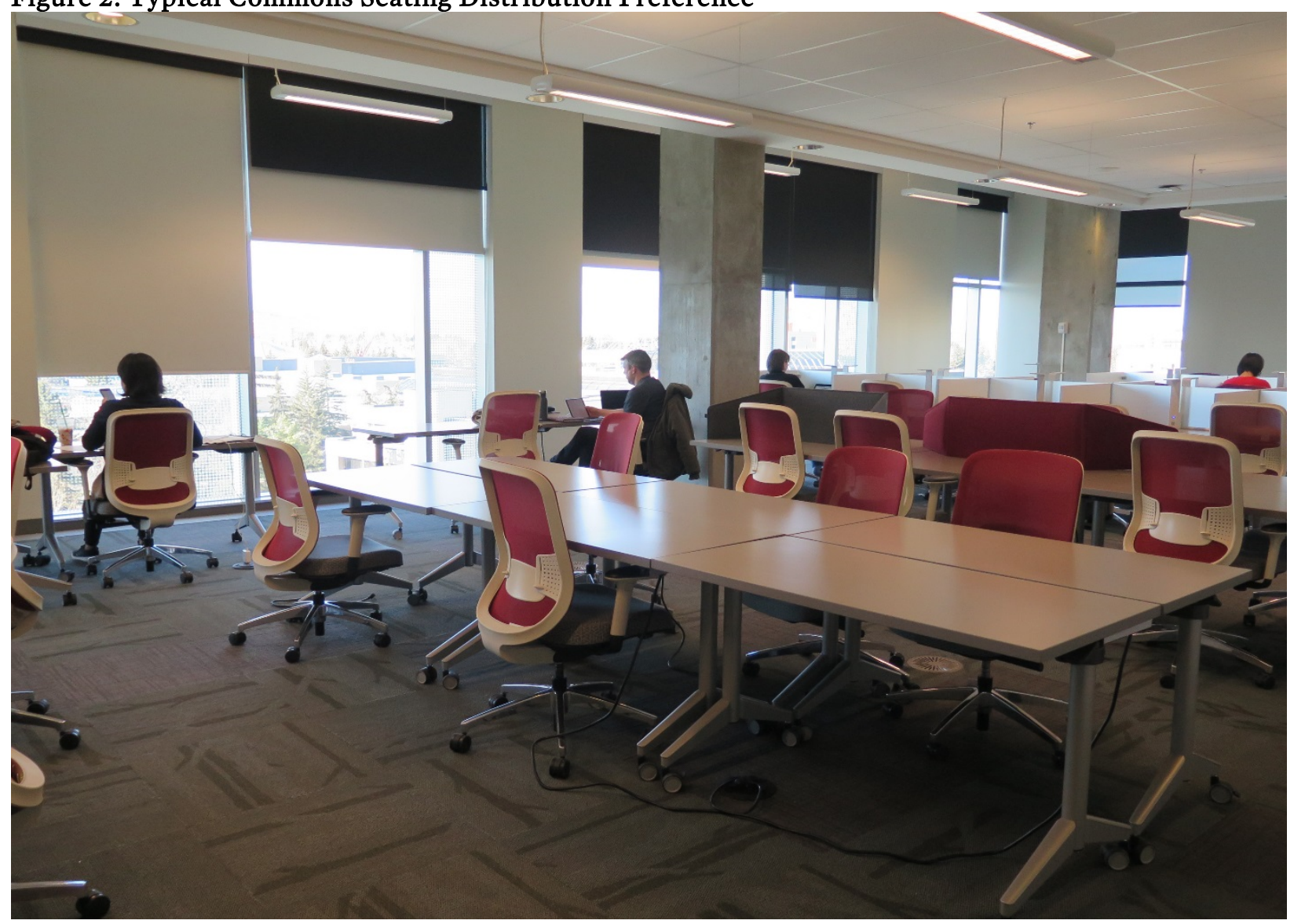

Figure 2 above shows students distributed in the Commons with 4 students in the room. Two students are each sitting alone at a table quite removed from each other, at the window and facing outwards. The third and fourth students are seated at carrels far from each other and both facing away either at the window or away from the door, facing the wall. They each have a defined space and also demonstrate a preference to work away from each other.

\section{What Do They Do?}

The students were asked to choose what they accomplish among a variety of tasks. The graduate students are a diligent group. Their goals are to read, study, write, and complete their assignments. They read predominantly articles $(\mathrm{N}=32)$, books, $(\mathrm{N}=23)$ and their notes $(\mathrm{N}=18)$. They are writing research papers $(\mathrm{N}=39)$ and research notes $(\mathrm{N}=21)$. They were more forthcoming in their comments about their specific priorities and activities.

\section{What Do They Bring?}

All students, with the exception of the one who kept a laptop in their locker, brought a laptop to the Commons. There are no PCs provided in the room. The laptop is the main device, even more so than cell phones $(\mathrm{N}=34)$ or other personal devices $(\mathrm{N}=11)$. They came prepared to work with print books, digital books, articles, and notes to read and brought something to eat. UofC is a commuter campus, and it is logical that they will all have a large bag or backpack as well as everything that they need for the day. Lockers were very much appreciated as they were directly accessible in the room and well-used to store personal items and checked out library materials. 


\section{Facility Rating}

Students were asked to rank out of five (the highest) the various features of the Commons. Below in Figure 3 are the cumulative rankings for the main features of the space: chairs, tables, study carrels, lockers, lighting (natural, desk, overhead), power outlets, internet access (Wi-Fi), view, windows, dividers, colors, cleanliness, environment (HVAC). While the majority of features ranged in the 4-5 out of 5 ranking, indicating a high level of satisfaction, there were some areas of lower ranking. The least-favored elements of the room were cleanliness and temperature. The top-favored were the windows and the view. While cleanliness is an issue that can be resolved, temperature control is the real problem in this room. A floor fan has been added to the room to improve the HVAC.

\section{Figure 3: Cumulative Graduate Commons Facilities Rankings}

\section{Cumulative Graduate Commons Facilities Rankings}

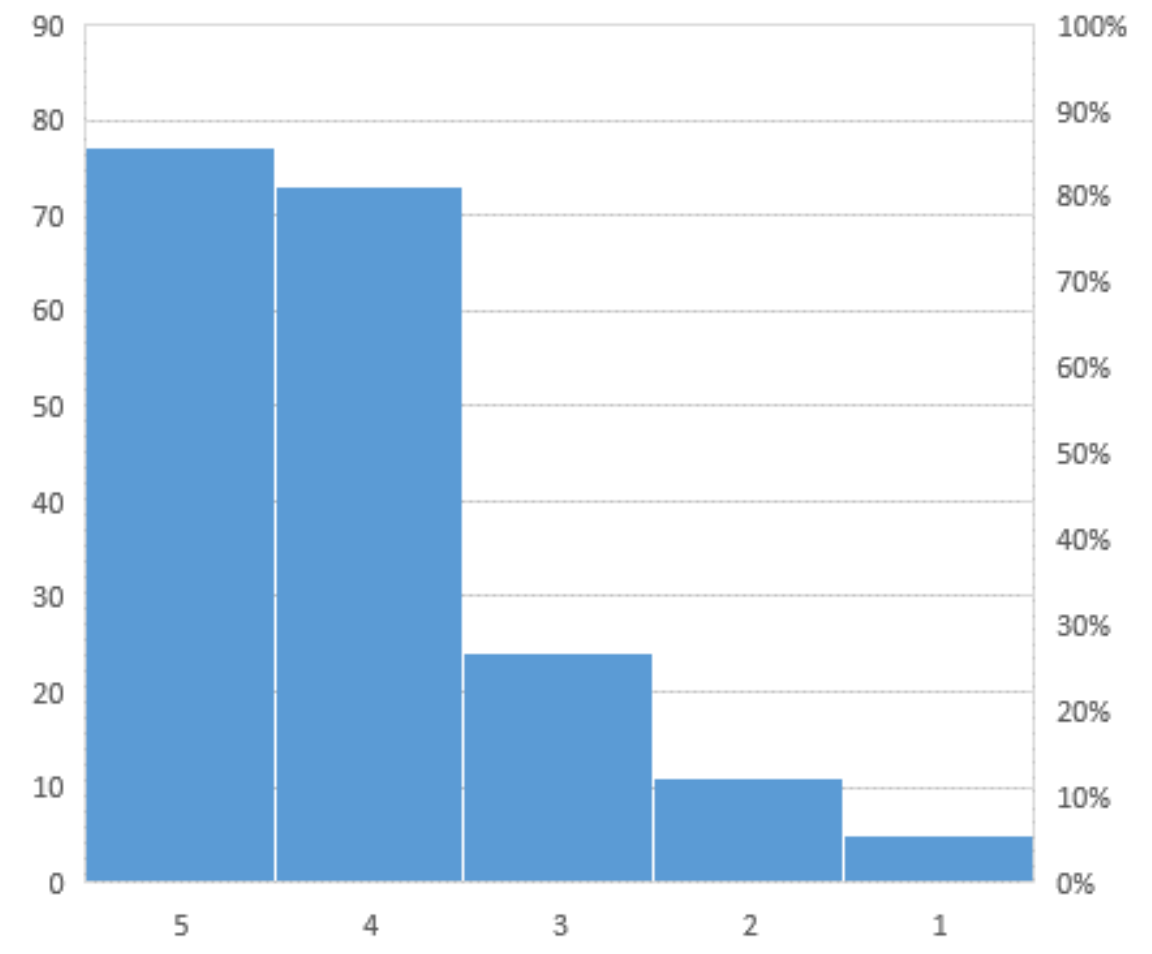

\section{Summary of Comments General Comments}

For the most part, the comments from the students were positive and focused on the space as a place where they can get their work done. Overall, the positive affirmations referred to the space as a quiet space with words such as "amazing," "wonderful," and "love." Specific affirmative comments referred to the aspects of the room that appealed, such as windows, light, and view. Generally, their comments, such as "get my best work done," "get meaningful work done," "productive," and "essential work done," indicated that the space supported their activities. Additionally their affirmations also mentioned emotional affects such as "more relaxed" and "more focused." For those who had a negative comment or a comment focused on improvement, four factors stood out: heat (including air circulation, dry air, and cold); cleanliness; uncomfortable chairs (too small, hard to adjust); and noise disturbance (cell phone conversations as well as personal conversations). 


\section{Comments on Space}

Students expressed a number of specific comments on the positive value to them of various features. The table below (Figure 4) ranks the comments highest to lowest. Most comments received were on the quiet atmosphere (23), the view (18), and the natural lighting (16). Students appreciated the guaranteed seating (16) and the fact that they could work distraction free, by themselves (13), and in a private space (12). They did appreciate the lockers and the secure nature of the space (10), thus allowing them to leave and come back to the room with their belongings still in place. The fact that the space was reserved for graduate students only (10) also allowed them to feel some ownership for the space and to make it their own (6). In general, then, they like to work in an intensive way in a space that feels supportive of their tasks and allows them to control their environment over a long period of time.

Figure 4: Number of comments on space

\begin{tabular}{|l|l|}
\hline Feature & Number of comments \\
\hline Quiet & 23 \\
\hline View & 18 \\
\hline Natural light & 16 \\
\hline Guaranteed seating & 16 \\
\hline Distraction/alone & 13 \\
\hline Private & 12 \\
\hline Secure/locker & 10 \\
\hline $\begin{array}{l}\text { Graduate students } \\
\text { only }\end{array}$ & 10 \\
\hline $\begin{array}{l}\text { Ownership of } \\
\text { space/flexible }\end{array}$ & 6 \\
\hline
\end{tabular}

\section{Seating Choice}

As with the previously studied undergraduate students, these graduate students tend to choose a space that meets their learning preferences. Given that this space has little variety, students do not have as much choice as elsewhere in the library. However, they did comment on their choice being dictated by such concerns as the need to be alone, either away from the sun or near a window; the need for as much space as possible; or the need to be aware of who is coming into the space. One student commented that the choice of seating was just natural. Students also commented on the need to feel relaxed, or that the space feels right. These comments reflect the comments that undergraduates had in a previous study about seeking a space that makes them feel comfortable (a mental state rather than a physical state) and open to learning. ${ }^{8}$

\section{Activities}

The students commented on their scholarly activities and their ability to be productive. They were very forthcoming on the nature of their scholarly work. Specifically, writing a dissertation or thesis was mentioned 16 times, while 31 students noted that they were working on their research while in the Commons. They were involved in writing such things as a thesis chapter, complete dissertations, literature reviews, conference papers and other presentations, master's theses, research proposals, in addition to writing and editing articles and books. They were involved in research and reading: reading notes, preparing for exams, advanced research, organization of research, reading papers, as well as specific research-related activities such as transcribing and data analysis. Students also used the space and time to catch up with other tasks: e.g., email, employer research, application letters, and their teaching assistant or research assistant 
duties. They do indulge in some diversionary actions such as listening to music or podcasts or watching videos. It is clear that they are involved in many tasks during and throughout their time in the Commons. The following comment is reflective of the nature of their work: "...nice views helps me focus and be productive. I do most of my reading and research work here." It is clear that the graduate students who use the Commons are very actively involved in all aspects of their work.

\section{Why the Library?}

Students commented positively on the multifunctional aspect of being in the space: easy access to all study related amenities such as Wi-Fi, washrooms, library resources, printing, coffee, snacks, and water fountain. Primarily, students commented on their campus office being less than optimum, noisy, distracting, and too busy. One student commented on the fact that it is good to have options. Notably, while they were very clear on the type of work they accomplish, it is the level of productivity that is likely of more significance as illustrated by this comment: "I submitted three papers which was almost impossible in my own office."

\section{Suggestions for Improvement}

As noted previously, the top requests for improvement were for improved HVAC (ventilation and temperature control) and for more cleaning or the opportunity to clean the space themselves. There were suggestions on seating: better chairs, footrests under tables, taller chairs, easier to adjust, and more flexible table arrangement to offer an opportunity to not face across from someone else. There was a suggestion to add a rest area with soft seating for unwinding. Students requested more lockers and 24-hour access, as well as access over more than one term at a time. Some students would like to see an enforced quiet space with cell phones and conversation banned.

\section{Observations}

In their study of students' use of physical library space, Cha and Kim note that graduate students ranked the top five space attributes as noise, amount of space, crowdedness, comfort of furnishings, and cleanliness. ${ }^{9}$ The same attributes are valued by the undergraduate students in the study as well. These results align with what the graduate students in the survey indicated, specifically in the need for improvements. They would like to have a clean, silent room, with more comfortable chairs and soft seating. In their positive comments, they value the space that they have and the ability to be away from distraction which is afforded to them by the view and the isolation of the room. While design focused on these attributes is essential, it is important to note that the purpose of the design in library learning spaces should be for learning. ${ }^{10}$ If the design is appealing to the students and appears to enable them to meet their purpose, then they will use it to achieve their goals. It is apparent from the comments in the survey that the students feel that they are achieving their goals and that the space itself helps them do so. Students have benefited from the space by being more focused and therefore productive.

\section{Further Actions by the Library}

Since this survey, there have been some changes and enhancements. Registration limit has increased to 150 students. Post-doc students are now accepted in addition to graduate students. This increased registration number has not resulted in any over-crowding in the room. Hourly head counts of the room indicate that at most 10 students are using the room at any one time. There likely is more room for growth in terms of registration. Students now have access to the room over both fall and winter terms. A floor fan has been added to the room, but due to the nature of the HVAC in this LEED Gold building (hot water perimeter radiant heating and floor-installed fresh air diffusers), the ability to cool the room is limited. Antiseptic wipes are now in the room for the students to use.

Part of the purpose in providing space for graduate students is to attract more graduate students to the library and its services. In terms of services, programming is being offered in the room, and the latest feature is drop-in writing assistance offered twice a week by the Writing Support Centre. Signs are posted in the room notifying students of scheduled room events so that they can plan their work in the Commons accordingly. 


\section{Conclusion}

By going beyond the simple feedback survey focused on likeability, this survey yields results which illuminate desirable features of a graduate space that support and enhance student learning. Most students in the survey preferred the unique features of the Commons versus the spaces available to them across campus. They could get their work done faster and with fewer disruptions in the library space. Additionally, results further understanding of the behaviours and activities of the graduate students and the value of identifiable spaces for graduate students. By applying a better understanding of student learning behaviours in the library and the value unique library space holds for students to space planning and design, libraries can be a vital learning space for all. This is a message that should be taken across campus.

\section{-Copyright 2019 Susan Beatty}

\section{References}

1. Office of Institutional Analysis, Fact book 2016-2017, University of Calgary, accessed October 31, 2018, https://oia.ucalgary.ca/fact-books/fact-book-20162017.

2. Susan Beatty, "Students' Perception of Informal Learning Spaces in an Academic Library: an Investigation into the Relationship Between Learning Behaviours and Space Design," in Proceedings of the IATUL Conferences, Paper 1 (2017) http://docs.lib.purdue.edu/iatul/2016/spaces/1.

3. Sharon Ince, "Trends in Academic Libraries Graduate Student Services: a Case Study," The Journal of Academic Librarianship 44 (2018): 426-429, doi https://doi.org/10.1016/j.acalib.2018.02.012.

4. Kirsten Kinsley, Rachel Besara, Abby Scheel, Gloria Colvin, Jessica Evans Brady and Melissa Burel, "Graduate Conversations: Assessing the Space Needs of Graduate Students," College \& Research Libraries 76, no. 6 (2015): 756-770, https://doi.org/10.5860/crl.76.6.756.

5. Hannah Gascho Rempel, Uta Hussong-Christian, and Margaret Melinger, "Graduate Student Space and Service Needs: a Recommendation for a Cross-campus Solution," The Journal of Academic Librarianship 37, no. 6 (2011): 483.

6. Beatty, "Students' Perceptions."

7. Beatty, "Students' Perceptions."

8. Beatty, "Students' Perceptions."

9. Seung Hyan Cha and Tae Wan Kim, "What Matters for Students' Use of Physical Library Space?" The Journal of Academic Librarianship 41, no. 3 (2015): 274-279, http://dx.doi.org/10.1016/j.acalib.2015.03.014.

10. Scott Bennett, "Putting Learning into Planning," Portal: Libraries and the Academy 15, no. 2 (2015): 215231. 